\title{
O Tempo Integral na visão dos alunos de uma escola pública do Ceará
}

\author{
Cláudia Denise Sousa De Moraes \\ Universidade Estadual do Ceará - UECE \\ Isaurora Cláudia Martins de Freitas \\ Universidade Estadual do Ceará - UECE
}

\begin{abstract}
Resumo
A implementação das Escolas de Ensino Médio em Tempo Integral (EEMTI) na Rede Estadual do Ceará ocorreu no ano de 2016, realizada pela Secretaria de Educação Básica do Ceará (SEDUC). Tal política vem acarretando mudanças no cotidiano das escolas onde o tempo integral vem sendo implantado e também na vida dos alunos. Neste artigo, analisamos as mudanças ocasionadas pela implantação do Tempo Integral na escola Jociê Caminha de Meneses a partir da percepção dos alunos. Para tal, foi realizada uma pesquisa de campo na referida escola, com alunos dos $3^{\circ}$ anos do Ensino Médio em Tempo Integral. Os participantes responderam a perguntas por meio de questionários e entrevistas emitindo suas opiniões sobre o regime de Tempo Integral. Entre os pontos elencados pelos jovens destacam-se aspectos positivos (a relação harmoniosa entre professores e alunos e a criação das disciplinas Eletivas como ferramenta importante no processo de ensinoaprendizagem) e aspectos que precisam ser melhorados: a infraestrutura da escola, a qualidade da alimentação e a participação da comunidade escolar no processo de implantação das políticas públicas dentro de uma escola.
\end{abstract}

Palavra-chave escola em tempo integral; políticas públicas de educação; qualidade da educação.

\begin{abstract}
The implementation of Full-Time High Schools (EEMTI) in the State Network of Ceará occurred in 2016, carried out by the Secretariat of Basic Education of Ceará (SEDUC). Such a policy has led to changes in the daily lives of schools where full-time has been implemented and also in the lives of students. In this article, we analyze the changes caused by the implementation of Full Time at the Jociê Caminha de Meneses school from the students' perception. To this end, a field research was carried out at the school, with students from the 3rd years of High School in Full Time. Participants answered questions through questionnaires and interviews giving their opinions on the Full Time regime. Among the points listed by the young people, positive aspects stand out (the harmonious relationship between teachers and students and the creation of Elective courses as an important tool in the teaching-learning process) and aspects that need to be improved: the
\end{abstract}


school infrastructure, the quality of education. food and the participation of the school community in the process of implementing public policies within a school.

Key-word full-time school; public education policies; quality of education.

\section{Introdução}

Face ao histórico problema da qualidade da educação pública no Brasil, a institucionalização da Escola em Tempo Integral tem sido defendida há tempos por estudiosos e gestores da educação como estratégia para promover avanços pedagógicos, inovações metodológicas, melhoria nas relações interpessoais e processos de aprendizagem significativa, possibilitando um melhor desenvolvimento dos educandos.

No Plano Nacional de Educação - PNE (Brasil, 2014), a Educação em Tempo Integral aparece como componente importante da atual agenda político-educacional, sendo destacada na Meta 06, que estabelece que esse regime de jornada escolar atinja 50\% das escolas públicas e atenda pelo menos 25\% dos alunos da educação básica até 2024 .

Segundo dados do Censo Escolar 2017, do Instituto Nacional de Estudos e Pesquisas Educacionais Anísio Teixeira (Inep), o Ensino Médio em Tempo Integral alcança apenas $8,4 \%$ dos jovens matriculados nessa modalidade. Os $91,6 \%$ restantes frequentam a escola no horário da manhã, da tarde ou da noite, em um período de quatro ou cinco horas diárias.

No Ceará, a Secretaria de Educação Básica apresentou, em 2017, com o objetivo de cumprir a Meta 06 do Plano Estadual de Educação (PEE), compilada da Meta 06 do PNE, o plano intitulado "Os sete Cearás" que tem "como um de seus objetivos assegurar a todo cidadão uma sólida formação educacional básica e fundamental, inclusiva e de qualidade, institucionalizando a Escola em Tempo Integral e modernizando a gestão educacional". (SEDUC, 2017).

A justificativa do Estado do Ceará para implementar a Escola de Tempo Integral se pauta, portanto, na defesa de uma educação que forme integralmente o educando. De que modo a educação em tempo integral vem sendo implantada nas escolas de Ensino Médio do Estado? O que dizem os alunos sobre esse modelo de escola?

Partindo dessas questões, este artigo, fruto de um estudo maior (MORAES, 2019) que buscou analisar os impactos do processo de implantação do tempo integral em uma escola da Rede Estadual de Educação Básica do Ceará, destacamos a visão dos alunos sobre as mudanças ocorridas com a ampliação do tempo escolar.

Deste modo, o presente estudo vem somar a outros já existentes no Brasil (VIEIRA (2003), CAVALIERE (2002, 2009), MOTA (2006), GONÇALVES (2006), FERREIRA (2007), ALMEIDA (2007), COELHO (2009)), que refletem sobre a educação em tempo integral em diversos aspectos, e diferencia-se dos demais por trazer à tona questões relacionadas à educação de tempo integral no Ceará a partir da ótica dos seus principais beneficiários, os estudantes.

Partimos do pressuposto de que ampliar a carga horária em si não significa melhorar a qualidade da educação. Alguns estudos que retratam as diferentes experiências em curso no país revelam que o tempo a mais na jornada diária deve significar avanços em direção à educação integral visando a multidimensionalidade do sujeito, a vivência de experiências culturais, artísticas, desportivas no espaço escolar, as mudanças curriculares, bem como um maior acesso à cidade como espaço educador (CAVALIERE, 2007; COELHO, 
2009; MOLL, 2012; MAURÍCIO, 2014). Escola em tempo integral, portanto, é diferente de educação integral.

Para Felício (2012), o conceito "educação integral" é polissêmico, não sendo possível compreendê-lo por meio de uma única maneira. Guará (2009) o define a partir de quatro perspectivas diferentes: formação integral do sujeito, articulando o processo educativo ao desenvolvimento humano (cognitivo, afetivo, psicomotor, social e outros); "[...] articulação entre as disciplinas curriculares e os conhecimentos em abordagens interdisciplinares e transdisciplinares" (GUARÁ, 2009, p. 5); articulação da escola com outros espaços comunitários, para garantir atividades no contraturno escolar; ampliação do tempo de permanência na escola com o desenvolvimento de atividades para melhorar o rendimento dos alunos. Portanto, não basta ampliar o tempo na escola para garantir educação de qualidade.

Em termos metodológicos, além da pesquisa bibliográfica, destinada a construir um arcabouço teórico que permitisse pensar a relação entre política educacional, escola de tempo integral e qualidade da educação, foi feita uma pesquisa em leis e documentos oficiais para conhecer o histórico e descrever a política de educação em tempo integral no Ceará e uma pesquisa de campo (GIL, 2008), realizada em 2018, para observar de perto o processo de efetivação do tempo integral na Escola de Ensino Médio Jociê Caminha de Meneses, localizada no bairro Bom Jardim, em Fortaleza-Ceará. A escolha desta escola justifica-se por ela ter sido uma das 26 escolhidas, em 2016, para iniciar a implementação do tempo integral e também porque a autora principal do artigo exerce a função de coordenadora pedagógica da Instituição. Na pesquisa de campo, técnicas quantitativas e qualitativas foram combinadas, permitindo, assim, uma análise que desse conta da complexidade da realidade e da temática em questão. (MINAYO, 1994). Deste modo, foram aplicados questionários e realizadas entrevistas semiestruturadas com 35 alunos do $3^{\circ}$ ano A e 34 do $3^{\circ}$ ano B. A escolha pelas turmas de $3^{\circ}$ ano se deu porque em 2018 estavam concluindo o ciclo de três anos da implantação de tempo integral iniciado em 2016.

Na primeira parte do artigo, tratamos da implantação e do funcionamento da educação em tempo integral na Escola Jociê Caminha de Meneses. Na segunda parte, analisamos as mudanças ocorridas na referida escola a partir das falas dos alunos.

\section{A implantação do tempo integral na Escola Jociê Caminha}

Embora a lei que formalizou esse projeto tenha sido sancionada no ano de 2017, na prática, a Educação em Tempo Integral em nosso estado iniciou no ano de 2008 com a criação das primeiras Escolas Profissionalizantes em Tempo Integral, no total de 25 escolas. Esse número foi crescendo gradativamente e em 2018 chegou a 119 escolas. Em se tratando do número de Escolas Regulares de Tempo Integral de Ensino Médio foram implantadas em nosso estado, no ano de 2016, as primeiras 26 escolas da Rede Pública do Ceará, sendo a Escola Jociê Caminha uma delas. No ano seguinte, foram criadas mais 45 escolas, totalizando 71. Em 2018, a rede contabilizou 111 Escolas Regulares em Tempo Integral. Além de Fortaleza, as Escolas de Ensino Médio em Tempo Integral estão distribuídas em 44 municípios e atendem 26.171 alunos. Tais escolas passaram a ter uma jornada diária entre 07 e 09 horas ou, no mínimo, 35 horas/semana.

Partindo do ponto de vista de que há uma complexidade e uma tensão na relação das juventudes com a escola (DAYRELL, 2007), a SEDUC propôs alterações no currículo escolar levando em consideração as potencialidades, os direitos de aprendizagem e o 
desenvolvimento pleno dos estudantes (SEDUC, 2017, p. 08). Assim, o projeto pedagógico das EEMTI pauta-se na necessidade de estruturar uma escola que atenda as necessidades e anseios das diversas juventudes a partir de três princípios: a escola como Comunidade de Aprendizagem; a Aprendizagem Cooperativa como método pedagógico estruturante e o Protagonismo estudantil como princípio imperativo. 0 primeiro princípio está relacionado às interações no ambiente escolar e à participação da comunidade. 0 segundo visa promover uma organização pedagógica pautada na interação entre os estudantes. E, por fim, a escola deve dar ênfase ao papel do jovem como centro do processo educativo.

A partir desses princípios se erguem quatro dimensões pedagógicas: a pesquisa como princípio pedagógico; o trabalho como princípio educativo; a desmassificação do ensino e os itinerários formativos diversos. Na prática, essas dimensões são concretizadas a partir de um modelo curricular que mantém 30h/a semanais correspondente à base curricular comum e mais $15 \mathrm{~h} / \mathrm{a}$ de atividades diversificadas assim divididas: $4 \mathrm{~h}$ destinadas ao Núcleo de Trabalho de Pesquisa e Práticas Sociais - NTPPS, 1h ao Projeto Professor Diretor da Turma, que oferece a cada turma um acompanhamento individual e coletivo mais específico, e 10h aos Tempos Eletivos, componentes curriculares que compõem a parte flexível do currículo e que são escolhidos semestralmente pelos alunos a partir de um catálogo disponibilizado pela SEDUC. O NTPPS trabalha o desenvolvimento das competências pessoais, motivando os alunos a participarem de experiências educativas significativas, entender as tendências e exigências da vida acadêmica e do mercado de trabalho, em três eixos principais: Projeto de Vida, Mundo do Trabalho e Iniciação à Pesquisa Científica. Aqui os alunos são motivados a fazerem bom uso de oportunidades educativas relacionando-as às tendências atuais do mercado de trabalho, à vida em sociedade e às exigências da vida acadêmica, visando prepará-los para a entrada na universidade.

A Escola Jociê Caminha de Meneses segue esse Projeto Pedagógico e em termos de disciplinas eletivas oferece com mais frequência canto coral, violão, práticas laboratoriais, jogos coletivos e preparação para o Exame Nacional do Ensino Médio (ENEM) a pedido dos alunos.

A unidade escolar foi fundada em 1987 como escola de 1o Grau. Posteriormente incorporou o ensino médio e até 2015 era em tempo parcial composta por três turmas de $8^{\circ}$ anos, três de $9^{\circ}$ anos, cinco de $1^{\circ}$ anos, cinco de $2^{\circ}$ anos e cinco de $3^{\circ}$ anos, totalizando 21 turmas, nos turnos manhã, tarde e noite. Em 2016, a escola iniciou a implantação gradativa do tempo integral, retirou os $8^{\circ}$ anos e posteriormente os $9^{\circ}$ anos, de modo que, em 2018, passou a contar com duas turmas de $1^{\circ}$ ano, três de $2^{\circ}$ ano e duas de $3^{\circ}$ ano, totalizando sete turmas, todas em tempo integral. 0 espaço físico compreende 09 salas de aula, 01 sala de professores(as), 01 sala de direção, 01 sala da coordenação, 01 secretaria, 01 sala de multimeios, 01 laboratório de informática, 01 laboratório de ciências, 01 cozinha, 04 depósitos, 01 despensa, 01 quadra poliesportiva, 01 pátio coberto.

A escola está inserida no Grande Bom Jardim (GBJ), um composto espacial de dimensões regionais, constituído por cinco bairros de Fortaleza: Granja Lisboa, Granja Portugal, Bom Jardim, Canindezinho e Siqueira. Segundo o censo de 2010, a população era de 211 mil habitantes (IBGE, 2010), ou seja, 8,33\% da população de Fortaleza. Os cinco bairros estão entre os dez mais pobres da cidade e apresentam alto índice de violência e criminalidade, o que faz com que sejam estigmatizados como "os mais perigosos" da capital cearense. A maioria da população (60\%) do GBJ é jovem ( 0 a 29 anos), sendo que $58 \%$ tem entre 0 e 17 anos, o que demonstra que boa parte dos jovens está em idade escolar. No ano de 2017, o Bom Jardim e o Jangurussu foram os dois bairros que registraram o maior 
número de homicídios de adolescentes em Fortaleza. (CCPHA, 2017). Tais características contribuíram para que a Escola Jociê Caminha fosse escolhida como uma das primeiras escolas regulares a implantar o tempo integral em Fortaleza, o que, de certo modo, revela a crença de que manter os jovens por mais tempo na escola contribui para afastá-los da criminalidade.

Para Cavaliere (2007), a escola em tempo integral se mistura em várias concepções, sendo as principais a de cunho assistencialista, voltada para atender os necessitados, de maneira a suprir a deficiência de sua formação, uma escola que apenas ocupa o tempo dos indivíduos e a que procura fazer a função da família. Nessa perspectiva, como afirma Cavaliere (2007, p. 1029), a "escola não é o lugar do saber, do aprendizado, da cultura, mas um lugar onde as crianças das classes populares serão 'atendidas' de forma semelhante aos 'doentes'”. Noutra concepção, aparece a visão de escola de tempo integral voltada para a prevenção da "marginalidade". Assim, ela seria uma instituição onde os estudantes ficariam fora das ruas e das mazelas sociais, uma lembrança do que eram os reformatórios (CAVALIERE, 2007).

O tema é complexo, pois, na prática, o papel da Escola em tempo integral não pode se resumir a tirar os jovens da rua, porque a redução da violência e da criminalidade não pode ser responsabilidade apenas da escola. Sem políticas de redução das desigualdades sociais uma sociedade não consegue reduzir seus índices de criminalidade. 0 papel da escola é bem mais amplo e seus pilares fundamentais devem estar voltados para a aquisição de conhecimento, para o desenvolvimento socioemocional e para o exercício pleno da cidadania, tendo, portanto, uma função emancipatória na medida em que seja capaz de desenvolver o senso crítico dos indivíduos.

Um dos primeiros impactos percebidos na escola Jociê Caminha após a implantação do tempo integral foi a diminuição no número de matrículas, ocasionado pelo fato de que o tempo integral impede que o jovem estude e trabalhe ao mesmo tempo e, em se tratando de famílias de baixa renda, adiar a entrada do jovem no mercado de trabalho é um complicador. Por outro lado, houve também uma significativa redução nas taxas de repetência e evasão conforme mostra a Figura 3.

\section{Figura 1. Rendimento escolar dos alunos do Ensino Médio da Escola EEMTI Jociê Caminha de Meneses no triênio 2015/2016/2017}

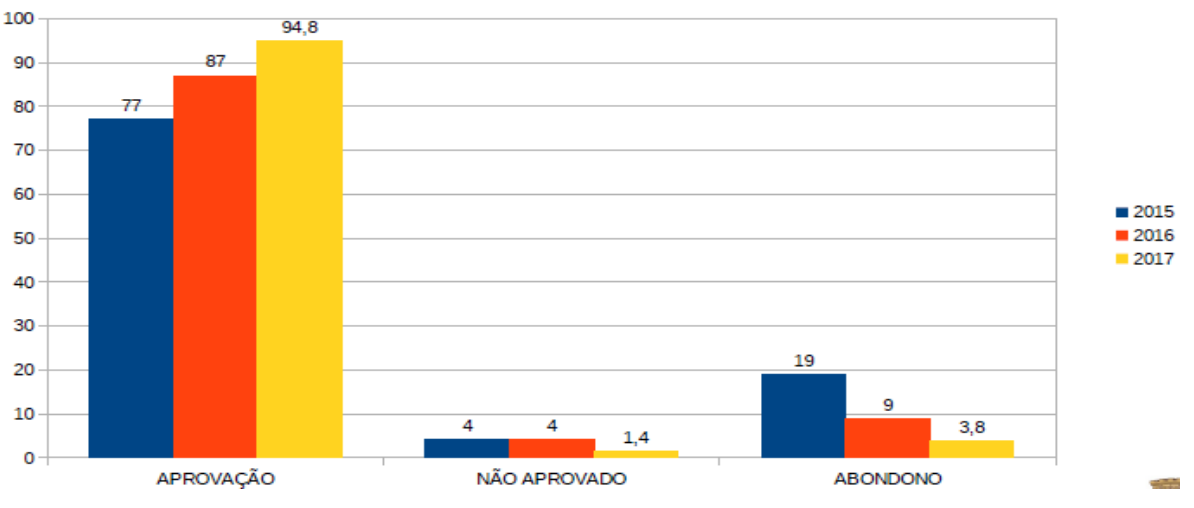

Fonte: SEFOR 03

A melhoria desses parâmetros em termos quantitativos nem sempre significa uma melhor aprendizagem. Muitas vezes, o que é medido não retrata as principais dificuldades 
apresentadas pelos alunos. A deficiência em áreas como interpretação e redação de textos é quase que "universal". 0 fato de tirar uma boa nota em uma avaliação ou trabalho para obter aprovação em uma determinada disciplina não pode ser considerado um modelo de eficácia garantida para o aprendizado. No entanto, a SEDUC usa esses resultados como forma de avaliar o sucesso ou não da Educação em Tempo Integral, o que não implica que o Programa não tenha limitações.

No caso da escola pesquisa, anualmente, são realizadas ações na tentativa de alcançar os alunos que começam e não terminam o ano, principalmente, quando estes demonstram desinteresse pelos assuntos curriculares. Assim, a escola tem procurado atrair os jovens promovendo atividades culturais, palestras educativas, aulas de campo, integração escola-comunidade e parcerias com outras instituições. Diante do exposto, vejamos a seguir como os alunos da escola percebem a escola em tempo integral.

\section{0 tempo integral na escola Jociê Caminha de Meneses na visão dos alunos}

A partir dos questionários aplicados, levantou-se que os alunos entrevistados possuem entre 17 e 21 anos de idade, sendo $52 \%$ do sexo masculino e $48 \%$ do sexo feminino. Em sua grande maioria os entrevistados afirmaram que suas famílias apresentam renda de até um salário mínimo e moram nas proximidades da unidade escolar. Devido a isso, afirmaram que se deslocam a pé até a escola.

Nas entrevistas semiestruturadas foram abordadas temáticas relacionadas às mudanças verificadas ocorridas a partir do momento em que começaram a frequentar o tempo integral na escola. Ao serem indagados sobre seus desempenhos escolares, a maior parte afirmou ser bom aluno. A autoavaliação, segundo eles, foi pautada nos seus esforços pessoais, na assiduidade nas aulas, na realização das atividades escolares e na participação nas eletivas, como se pode verificar pelas falas: "Me considero uma boa aluna porque nunca recebi nenhuma reclamação dos professores. [...] não falto às aulas, não chego atrasada, tiro sempre notas boas, não deixo de fazer os trabalhos que são passados e participo das eletivas" (Cida1, 17 anos); "Tiro notas boas nas avaliações e faço todas as atividades que os professores passam. Além disso, procuro prestar atenção em todas as aulas, não chegar atrasada ou faltar[...]. Gosto também de participar das eletivas" (Laura, 17 anos).

A visão sobre os estudos merece destaque, pois aponta para aspectos que são trabalhados nos alunos a partir das atividades do NTPPS, sobretudo as relacionadas ao Projeto de Vida. Assim, afirmam que estudam para ter uma profissão no futuro, porque querem aprender mais, porque gostam da escola e porque querem ajudar financeiramente os pais. Beto (18 anos), afirmou que estuda "[...] pra ser alguém melhor e não desapontar meus pais." E complementa: "Meus pais depositam muita confiança em mim. Acham que se eu estudar posso ter um bom emprego no futuro. 0 sonho deles é me ver formado". Nessa mesma vertente, Bruna (17 anos) diz: "Estudo pra ter uma profissão no futuro e ajudar meus pais financeiramente. Meus pais são pobres e não tem uma boa condição financeira. Espero me formar e conseguir um bom emprego e dar uma vida melhor para os meus pais".

Ao falar sobre o ensino oferecido pela escola, destacam as mudanças na metodologia adotada pelos professores. Para eles, com o tempo integral, os professores passaram a se empenhar mais e a estar mais disponíveis aos alunos. Um aluno destacou o seguinte: "Os professores da escola muitas vezes agem com a gente como se fossem da família ou até

1 Para preservar a identidade dos entrevistados, todos os nomes que aparecem no texto são fictícios. 
fazem mais do que nossos familiares. No meu caso é comum os professores conversarem comigo me aconselhando a não fazer coisas erradas e procurar sempre fazer o bem. Me orientam pra sempre me dedicar aos estudos." (Alan, 17 anos). Outra aluna destaca que "o foco de ensino tem se direcionado ao Enem e vestibulares como da UECE2" (Bianca, 17 anos).

Os alunos destacaram o clima de amizade com os professores afirmando que se sentem valorizados pelos mesmos. Pedro (17 anos) destacou que: "Os professores acreditam muito na nossa capacidade e muitas vezes agem como conselheiros não se resumindo somente a dar suas aulas. É comum os professores conversarem com a gente nos corredores da escola sempre nos incentivando a melhorar nosso rendimento" (Pedro, 17 anos).

A grande maioria dos entrevistados afirmou que a mudança de regime parcial para tempo integral ajudou a melhorar a aprendizagem e que a escola atual proporciona uma educação de boa qualidade. É o que afirma Paula (17 anos), ao dizer que "A escola de tempo integral dá para adquirir mais conhecimentos, tem mais aulas e atividades voltadas para o mercado de trabalho". Perguntados sobre o que seria para eles uma escola de boa qualidade, responderam que ela deveria ter boa estrutura física, professores competentes e alunos interessados.

A definição de escola de qualidade vai além do prédio e dos que lá trabalham ou estudam. Corpo gestor, docentes e discentes têm uma função primordial no sucesso de uma unidade escolar, mas, por trás deles há uma equipe de profissionais que desenvolvem novas metodologias de ensino, captam e gerenciam os recursos financeiros destinados à educação. Logo, o conceito de escola de qualidade passa por: maiores investimentos na educação, capacitação dos profissionais, elaboração de políticas públicas que procurem melhorar o ensino das escolas se adequando à realidade atual e ao desenvolvimento de novas metodologias de ensino. Esses avanços influenciam naquilo que os alunos consideram escola de qualidade: boa estrutura física, professores compromissados e alunos interessados.

Com relação às disciplinas eletivas, nas entrevistas, os alunos as definiram como sendo práticas e diferentes, o que ajuda de alguma forma na aprendizagem, mas, contraditoriamente, $58 \%$ dos que responderam ao questionário afirmaram que os professores dessas mesmas disciplinas não ministram aulas inovadoras.

Os jovens também elencaram os pontos negativos da escola após a implantação do tempo integral. Dentre eles, destacamos a questão da estrutura física e da alimentação. No que se refere à estrutura física, a falta de espaços adequados para a realização de algumas atividades é o grande problema. A falta de refeitório e de espaço para o descanso após o almoço, por exemplo, é alvo de muitas críticas. No quesito alimentação, o maior problema apontado foi a má qualidade da alimentação e a falta de um cardápio mais diversificado, pois consideram o cardápio repetitivo. Carlos (17 anos) destacou que: "A escola precisa melhorar a alimentação, pois a comida não é de boa qualidade. E também não tem um local para descansar após o período do almoço. Normalmente a gente vai pra a biblioteca. Queríamos que tivesse um local só pra descanso, onde a gente pudesse dormir um pouco".

Sobre a quantidade de horas que passam na escola, muitos afirmaram sentir cansaço após o almoço e ao final do dia letivo e, mais uma vez, a necessidade de um lugar propício ao descanso aparece: "Deveria ter um maior tempo de descanso após o almoço, pois nesse

2 Universidade Estadual do Ceará. 
horário é normal que a gente sinta mais sono. Deveria ter um local específico para tirarmos uma soneca" (Leandro, 17 anos).

Para outros, o tempo a mais que passam na escola tem um papel importante para "evitar que os jovens fiquem na rua". Essa opinião corrobora com a ideia do próprio governo do Estado e da SEDUC sobre a educação em tempo integral ser um fator redutor da criminalidade. Deste modo, a existência de escolas em tempo integral acaba sendo justificada como ação preventiva, conforme discussão contida no item anterior deste texto.

Levando em conta as críticas dos jovens sobre o espaço físico da escola, é importante ressaltar que não houve preparação do ambiente para a recepção do novo modelo, o que implicou numa condição de insalubridade, pois os estudantes permaneceram por um período prolongado em salas sem climatização, além de não haver refeitório e espaços adequados para o descanso. A escola encontra-se em condição de reforma há pelo menos três anos. Dentre as mudanças realizadas até agora estão: reforma nos banheiros, reforma na quadra, ampliação da cozinha, com almoço self service e, mais recentemente, a instalação de câmeras e de ar condicionados nas salas. Quando da implantação do tempo integral, a SEDUC também não fez consulta prévia ao corpo docente, ao corpo discente e aos pais.

O exposto acima serve para mostrar que nem sempre a formulação e implementação de uma política pública se dá como tem que ser e isso pode ocasionar a sua ineficiência e ineficácia. No Brasil, os formuladores dos programas educacionais muitas vezes não apresentam conhecimento pedagógico e muito menos prática de docência. É comum estarem alheios à realidade dos alunos e das escolas. Nesse contexto, é incompreensível não incluir a comunidade escolar na elaboração de qualquer política pública voltada para educação. Na maioria das escolas do Ceará, assim como na EEMTI Jociê Caminha de Meneses, a mudança para o regime de tempo integral se deu sem a escola estar preparada.

Apesar das críticas, os entrevistados afirmaram gostar da escola e disseram que não mudariam para outra. Uma aluna destacou o seguinte: "Saí uma vez da escola, mas me arrependi e voltei. Quando fui pra outra escola vi que muitas coisas eram diferentes. Não tinha as mesmas amizades e isso me fazia não sentir muita vontade de ir às aulas" (Laís, 17 anos). Nesse sentido, vamos perceber também a escola como espaço de sociabilidades, onde os jovens constroem laços e redes de afeto com seus pares que muitas vezes contribuem mais para a permanência deles na escola do que a dimensão pedagógica.

Em geral, os resultados aqui apresentados mostram que a implementação do Tempo Integral na Escola Jociê Caminha de Meneses permitiu aos alunos uma mudança de postura e pensamento, pois não é só a escola que deve se adaptar às mudanças, mas os alunos também precisam se adequar à nova proposta de ensino. 0 próprio aumento na carga horária requer dos alunos uma maior disposição e disponibilidade de tempo para estarem na escola. $\mathrm{O}$ fato de passarem mais tempo na escola faz com que eles tenham que abdicar de atividades de lazer, mais tempo com a família e até mesmo do emprego, o que se torna um complicador para as famílias cuja sobrevivência necessita da renda de todos os seus membros. Na visão da maioria deles, a decisão de estar numa escola de tempo integral pode render benefícios futuros que compensem as renúncias do presente.

Portanto, eles deixaram de ver a escola somente como uma oportunidade de aprender assuntos relacionados a disciplinas básicas e começaram a vê-la como uma aposta para que, no futuro, concorram com mais chances no mercado de trabalho, mesmo que, com a mudança de regime, problemas antigos ainda persistam na escola. 


\section{Considerações Finais}

Procuramos neste texto mostrar como os alunos percebem as principais mudanças que aconteceram na Escola Professor Jociê Caminha de Meneses a partir da introdução do tempo integral. A partir de 2016, período em que a escola implantou esse modelo educacional, ela tem passado por diversas mudanças. Dentre as principais citamos: as mudanças na estrutura física, maior tempo de permanência dos alunos na escola, acompanhamento mais específico por aluno, mais empenho por parte dos professores e mudanças para adequação de um novo currículo pela introdução do NTPPS e das disciplinas eletivas que permitem novos conhecimentos além aqueles adquiridos pelas disciplinas básicas. Tais mudanças reverberam na vida dos alunos de modo que, em suas falas, puseram em relevo aspectos positivos: melhoria na aprendizagem e nas relações interpessoais no ambiente escolar, a mudança de mentalidade dos alunos que passaram a ver nesse novo modelo uma oportunidade de conseguir melhor futuro profissional e a consolidação da cultura de continuidade dos estudos após o término do ensino médio, através do ingresso no ensino superior. 0 que se via antes na escola era apenas o desejo de terminar o ensino médio e procurar um emprego, quando não a abandonavam.

Com relação à carga horária exigida pelo tempo integral, há condições diferentes de se vivenciar o tempo de escola. Em primeiro lugar, o tempo diário que os alunos passam na escola tem se tornado um obstáculo, pois muitos querem associar o estudo ao trabalho. Isso acaba sendo um dos principais motivos para a diminuição do número de matrículas, pois os jovens precisam trabalhar mais cedo devido às condições financeiras de suas famílias. Certamente este é um grande entrave para a política educacional de tempo integral que visa "universalizar" o acesso ao ensino médio.

Sabemos que a política de EEMTI se destina aos jovens de baixa renda que residem em comunidades vulneráveis socioeconomicamente e expostos à violência. Sendo essa política educacional associada à "segurança" e à "proteção" dos jovens, uma das suas principais dimensões está relacionada a "tirar os jovens da rua" e a "mantê-los longe das drogas e da criminalidade". Isso por si só não garante seu sucesso, pois não se pode estigmatizar os jovens como os responsáveis pelo problema da violência e da criminalidade sem considerar diversos outros fatores que podem influenciar diretamente na inserção desses problemas na sociedade atual, como, por exemplo, a desigualdade social.

Quando se trata da relação aluno e escola, os estudantes apontaram diferentes aspectos: a qualidade dos professores e a forma como são tratados por eles; os funcionários; a maior possibilidade de estudar e aprender e o aspecto relacional que a escola oferece, sobretudo, como espaço que proporciona a construção de amizades. Tais fatores são características positivas atribuídas ao tempo de escola. Todavia, o fato de passarem 09 horas diárias na Instituição acarreta muitas vezes cansaço e sono nos estudantes, principalmente após o almoço o que é agravado pelo fato de não haver um espaço adequado para o descanso.

A pesquisa aponta para a importância de ouvir os alunos sobre os impactos da implementação do Tempo Integral, pois a visão deles traz elementos que fogem muitas vezes ao olhar dos profissionais da educação. Saber o que pensam sobre as mudanças ocorridas na escola é fundamental para repensar metodologias de trabalho, idealizar novos projetos, discutir novas eletivas, fazer adequações no PPP da escola.

A partir dos dados levantados, percebemos que há ainda desafios a serem vencidos: melhoria da infraestrutura e da alimentação, aumento do número de matrículas, maior 
participação da comunidade escolar na tomada de decisões sobre as mudanças na política educacional e, sobretudo, produção constante de processos que permitam avaliar os impactos das mudanças, levando em conta as falas dos beneficiários.

\section{Referências bibliográficas}

CAVALIERE, A. M. V. Tempo de escola e qualidade na educação pública. Educação\& Sociedade. Campinas, v.28, n.100, out. 2007.

CAVALIERE, A. M. V. Escolas de tempo integral versus alunos em tempo integral. In: MAURICIO, L. V. Em aberto. Brasília, v.22, n.80, 2009.

COELHO, L. M. C. C. História(s) da Educação Integral. In: MAURICIO, L. V. Em aberto. Brasília, v.22, n.80, 2009.

FELÍCIO, H. M. S. Análise curricular da escola de tempo integral na perspectiva da educação integral. Revista e-curriculum, São Paulo, v.8, n.1, abr. 2012.

GUARÁ, I. M F. R. Educação e desenvolvimento integral: articulando saberes na escola e além da escola. Em Aberto, Brasília, v. 22, n. 80, p. 65-81, 2009.

MOLL, J. Caminhos da educação integral no Brasil: direito a outros tempos e espaços educativos. Porto Alegre: Penso, 2012. 504p.

MAURÍCIO, L. V. Tempos e espaços escolares: experiências, políticas e debates no Brasil e no mundo. Rio de Janeiro: Ponteio, 2014. 252p.

PINHEIRO, M. R. Ensino médio em tempo integral e seus sentidos: a experiência da escola Matias Beck em Fortaleza-Ce. 2018. 158f. Dissertação (Mestrado em Sociologia) Universidade Estadual do Ceará, Fortaleza-Ce, 2018.

ROCHA, J. A.; AMORIN, R. F.; PAULA, P. V. B.; SILVA, M. C. L.; ROCHA, E. D. F. Escola regular em tempo integral: implementação na rede pública estadual cearense. Revista do Programa de Pós-Graduação em Humanidades, Culturas e Artes, Rio de Janeiro, v.2, n.16, 145-169, 2017.

SECretaria de eduCAÇÃo do CEARÁ. Projeto Político Pedagógico: Ensino Médio em Tempo Integral na rede estadual do Ceará. Fortaleza, 2017. 